\begin{tabular}{|c|c|}
\hline CRITICAL $\left.\right|_{\substack{\text { ECORTNERSHIP FUND } \\
\text { PART }}}$ & $\begin{array}{l}\text { Western Ghats } \\
\text { Special Series }\end{array}$ \\
\hline
\end{tabular}

\title{
MULTI-STAKEHOLDER PERCEPTIONS OF EFFICIENCY IN BIODIVERSITY CONSERVATION AT LIMITED ACCESS FORESTS OF THE SOUTHERN WESTERN GHATS, INDIA
}

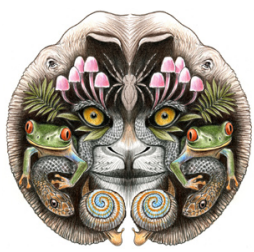

ISSN

Online 0974-7907 Print 0974-7893

OPEN ACCESS

\author{
Arun Kanagavel ${ }^{1}$, Revati Pandya ${ }^{2}$, Aditya Prithvi ${ }^{3}$ \& Rajeev Raghavan ${ }^{4}$ \\ ${ }^{1,4}$ Durrell Institute of Conservation and Ecology (DICE), School of Anthropology and Conservation, University of Kent, \\ Canterbury, CT2 7NR, United Kingdom \\ 1,2 Wildlife Information Liaison Development Society (WILD), 96, Kumudham Nagar, Vilankurichi Road, Coimbatore, \\ Tamil Nadu 641035, India \\ ${ }^{1,4}$ Conservation Research Group (CRG), St. Albert's College, Banerji Road, Kochi, Kerala 682018, India \\ ${ }^{3}$ Department of Econometrics, University of Madras, Chepauk, Chennai, Tamil Nadu 600005, India \\ ${ }^{4}$ Zoo Outreach Organization (ZOO), 96, Kumudham Nagar, Vilankurichi Road, Coimbatore, Tamil Nadu 641035, India \\ ${ }^{1}$ arun.kanagavel@gmail.com (corresponding author), ${ }^{2}$ revati.pandya@gmail.com, ${ }^{3}$ solar.ads@gmail.com, \\ ${ }^{4}$ rajeevraq@hotmail.com,
}

\begin{abstract}
Biodiversity conservation is a collaborative effort involving numerous stakeholders. Attempting to balance different interests and developing effective working relationships between stakeholders is vital for successfully addressing issues of biodiversity conservation. Presently, biodiversity conservation in India is monopolised by state forest departments (FD) with negligible participation from local communities (who are directly affected by forest laws) and researchers (whose work can improve conservation). This study examines the efficiency of multiple stakeholders'-local communities, FD, researchers and politicians in conserving biodiversity at the Anamalai Palni Hills of the southern Western Ghats in Tamil Nadu. 'Efficiency' here is defined as the amount of positive assistance stakeholders provide towards conserving biodiversity. A systematic sampling strategy through self-administered questionnaires was used to understand stakeholders' perception of one another and the challenges they faced. The results highlight the FD as having the highest efficiency in conserving biodiversity followed by local communities, researchers and lastly, political leaders. Stakeholder evaluation of one another's efficiency revealed a homogenous opinion towards local communities and the FD. However, a considerable difference was observed towards researchers whereby their efficiency was rated lower by local communities in comparison to the FD. Dependency on forest resources that was curbed by the FD invariably affected the attitude of local communities towards biodiversity conservation. On the other hand, low pay rolling schemes, inadequate facilities and political interference hinder the management capabilities of the FD. Increased research and outreach activities would benefit Kodaikanal and Theni, provided a collaborative effort to conserve biodiversity is pursued.
\end{abstract}

Keywords: Forest Department, Kodaikanal, local community, political leaders, researchers, Theni, Valparai.

DOI: http://dx.doi.org/10.11609/JoTT.03439.4529-36

Editor: Jeff McNeely, IUCN, Gland, Switzerland.

Date of publication: 26 July 2013 (online \& print)

Manuscript details: Ms \# 03439 | Received 16 December 2012 | Final received 13 May 2013 | Finally accepted 01 July 2013

Citation: Kanagavel, A., R. Pandya, A. Prithvi \& R. Raghavan (2013). Multi-stakeholder perceptions of efficiency in biodiversity conservation at limited access forests of the southern Western Ghats, India. Journal of Threatened Taxa 5(11): 4529-4536; http://dx.doi.org/10.11609/JoTT.03439.4529-36

Copyright: (C) Kanagavel et al. 2013. Creative Commons Attribution 3.0 Unported License. JoTT allows unrestricted use of this article in any medium, reproduction and distribution by providing adequate credit to the authors and the source of publication.

Funding: The study is a part of a larger project titled "Potential for community and conservation reserves in the southern Western Ghats" funded by the North of England Zoological Society (NEZS) through the Chester Zoo Studentships and the Durrell Institute of Conservation and Ecology (DICE), School of Anthropology and Conservation, University of Kent, Canterbury, UK.

Competing Interest: The authors declare no competing interests. Funders had no role in study design, data collection, results interpretation and manuscript writing.

Author Details, Author Contribution: See end of this article.

Acknowledgements: The first author would like to thank A. Kumar, K. Vijayalakshmi, P.A. Kanagavel, S. Kumar, and S. Satyanarayanan for helping with data collection and field logistics. Thanks are also due to the local communities, forest department officials and conservation researchers in the project area for participating in the survey.
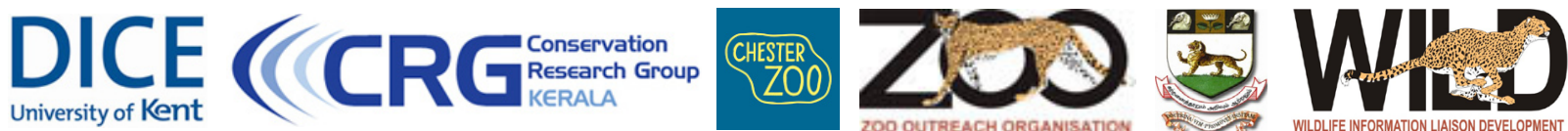

The publication of this article is supported by the Critical Ecosystem Partnership Fund (CEPF), a joint initiative of I'Agence Française de Développement, Conservation International, the European Commission, the Global Environment Facility, the Government of Japan, the MacArthur Foundation and the World Bank. 


\section{INTRODUCTION}

The conservation of biodiversity involves the interaction and collaboration of numerous stakeholders with varied interests and roles (Niraj et al. 2012). However, decision-making for managing forested areas in biodiversity rich countries like India is often unidimensional. Relevantstakeholderslikelocalcommunities who are directly affected by a conservation initiative and researchers who try to understand conservation issues and devise suitable strategies to resolve them are seldom considered or consulted (Madhusudan et al. 2006). This uni-dimensional approach, by omitting the perceptions of key stakeholders, undermines the effectiveness that could otherwise be achieved by integrating their perceptions, knowledge and support to inform management initiatives. Following are a few examples that indicate the importance of integrated involvement in biodiversity conservation. A huge local protest against the set up of a tiger reserve in Masinagudi, Tamil Nadu, was a result of lack of consultations with the people (Taghioff \& Menon 2010) and the fact that it was based on a strict preservationist-based protected area system. Similarly, in the case of sea cucumber harvest by local communities in the Coromandel Coast of India, where this taxa was brought under the list of prohibited species in the Indian Wildlife (Protection) Act without any consultations with the fisherman communities (Niraj et al. 2012). In both cases, there could have been a loss of positive attitudes among the locals and thereby, a loss of benefits to wildlife conservation and subsequently for the other key stakeholders. Local community participation in management could decrease issues related to protected area norms, its effect on local people and compliance (Andrade \& Rhodes 2012). There is a broad scope for local community participation in India, as there have been numerous informal initiatives headed directly by local communities. These have been termed as Community Conserved Areas, which are natural (like forests, marine ecosystems, wetlands, and grasslands), ecosystems with wildlife and biodiversity value, being conserved by communities for cultural, religious, livelihood or political purposes, using customary laws or other effective means (Pathak 2009).

Interactions between stakeholders who influence biodiversity conservation, and perceptions of each other's capabilities to address relevant issues are often not discussed. Varying perceptions and mistrust towards a stakeholder group from others, which the specific group may perhaps be unaware of, could diminish their role in conservation-related activities. Brown's (2002) discussion on integrated conservation and development strategies emphasised a trade-off analysis which included analyses of stakeholder interests, consensus building and discussing information regarding stakeholder perceptions. Stakeholder groups must be allowed to identify priorities before arriving at a consensus for working towards conservation. The Bucco Reef Marine Park, a tourist attraction in Tobago is a protected area with a coral reef, sea grass lagoon, mangroves, beach and coastal land (Brown 2002). The ecological systems were not well understood by the various stakeholders who used it's resources, thereby leading to a challenging and complicated management issue. Through interaction and discussions, these stakeholders were integrated as a part of the decision-making for conserving the island and a consensus was built through varying interests.

Through this study at limited access forest fragments of the southern Western Ghats, we aim to explore and inform the efficiency of key stakeholders- local communities, Forest Department (FD) and researchers, towards biodiversity conservation and to understand issues between and within each.

\section{METHODS}

\section{Study Area}

The study was conducted in three areas, Kodaikanal, Theni and Valparai situated in the Anamalai-Palni Hills of the southern Western Ghats (Fig. 1).

The city of Kodaikanal, a popular tourist destination located in the Dindigul District covers an area of $1039 \mathrm{~km}^{2}$. A watershed for the Vaigai and Manjalar rivers, it supports a diverse flora, which is found in the dry deciduous forests and 13 unique shola forests (Bagyaraj \& Gurugnanam 2011). Land use includes vegetable farming as well as coffee plantations, surrounded by densely populated human settlements. Converting forest areas into terraces for farming and, agricultural lands to tourism-related infrastructure has resulted in extensive soil erosion, silting of water sources and an increased risk of landslides (Bagyaraj \& Gurugnanam 2011)

The district of Theni is located in the southwest part of Tamil Nadu bordering the Kerala State (CARDS 2008). The elevation ranges from 100 to $1800 \mathrm{~m} \mathrm{ASL}$ and the area forms a catchment for the rivers Suruli, Mullaperiyar, Vaigai and Kottagudi (District Collectorate Theni 2009; Ayyanar et al. 2010; Bhupathy et al. 2012). Vegetation types vary between the plains and regions of high altitude, with the former predominantly consisting 


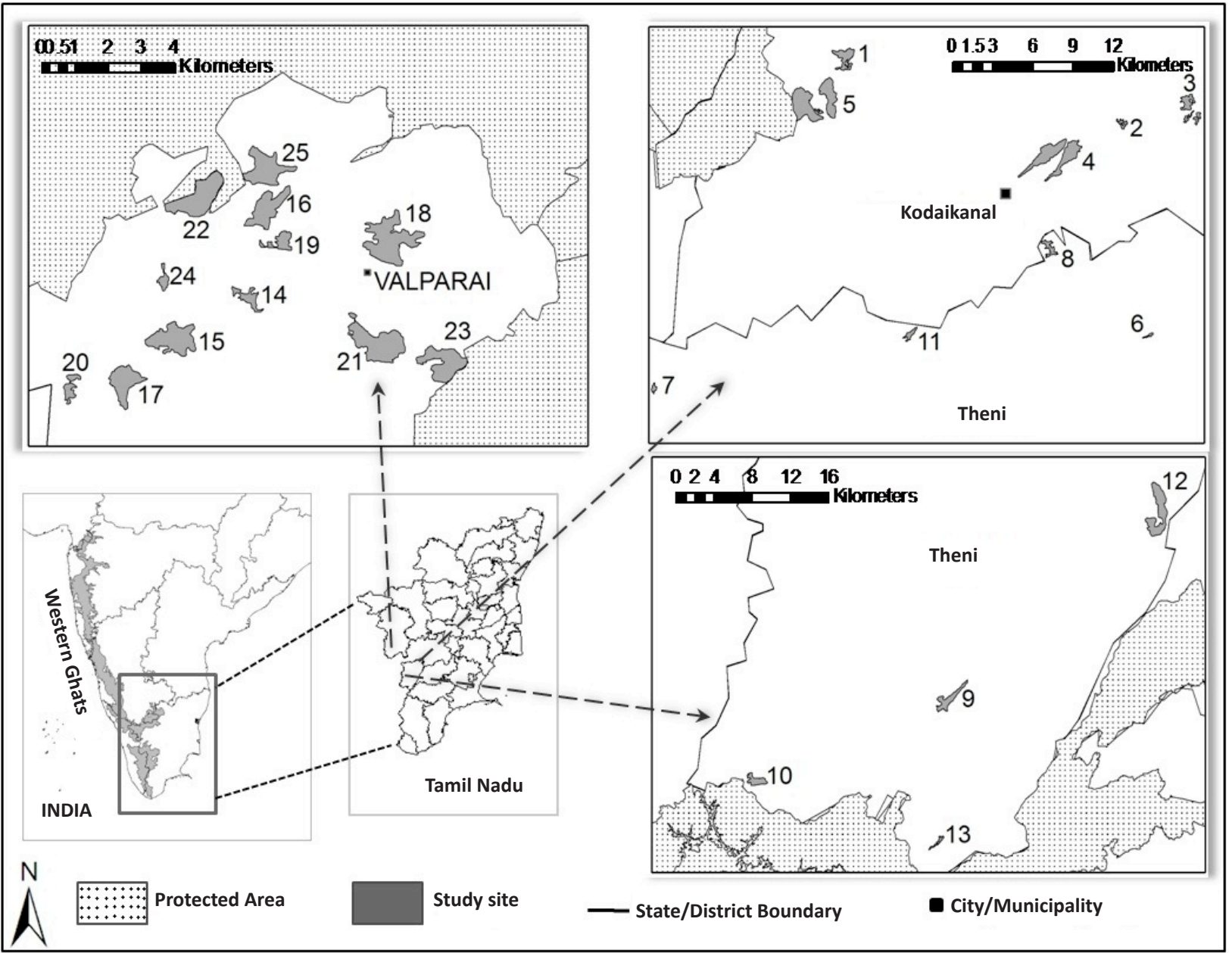

Figure 1. Map of the study sites at Valparai, Kodaikanal and Theni and their location within the state of Tamil Nadu in southern India. Refer to Site No. in Appendix 1 for the identity of study-sites. Study-sites were digitized using LISS III data and shape files obtained from the local collaborator, Conservation Research Group, St. Albert's College, Kochi and VDS Technologies <http://www.vdstech.com/map_data.htm>

of southern tropical forests and the latter, dry and moist deciduous and evergreen forests (Ayyanar et al. 2010). Primarily an agriculture-based economy, Theni is known for its cardamom, cotton, mango, coffee and tea plantations (District Collectorate Theni 2009). Prone to unsustainable cultivation practices and encroachment, the forest cover in the district is under considerable strain (Raju 2002).

The municipality of Valparai located in the district of Coimbatore is contiguous with the Vazhachal Reserve Forest of Kerala (Raman \& Mudappa 2003). It harbours forest types ranging from tropical dry scrub, dry deciduous, moist deciduous, semi-evergreen and evergreen forests to montane shola grasslands (Daniels 2003; Muthukumar et al. 2006). Nearly 1000 acres of degraded rainforest fragments are distributed across coffee, tea and cardamom estates, surrounded by four protected areas, viz., Indira Gandhi Wildlife Sanctuary,
Chinnar Wildlife Sanctuary, Eravikulam National Park and Parambikulam Wildlife Sanctuary (Raman \& Mudappa 2003). Over the past years, increasing human population, forest fragmentation, human-wildlife conflict and a lack of dialogue between landowners and the FD have affected the ecological balance of Valparai (Raman \& Mudappa 2003).

\section{Interview survey}

Questionnaire surveys were conducted from May to July 2010 with individuals from the local community, FD officials and conservation researchers.

Surveys were undertaken with local communities close to, or within reach of the 25 Reserve Forests and private forest fragments (Fig. 1; Appendix 1). Systematic sampling strategy (Newing 2010) was used to select 20 households. At Kumbhakarai and Paliangudi only 10 households were selected due to time constraints. Within 
each household, the first individual above the age of 18, irrespective of gender, who consented, was interviewed. In total, 480 questionnaires were administered.

Questionnaires were administered with 21 FD officials (three at Kodaikanal, five at Theni and 13 at Valparai) and 11 conservation researchers (two at Kodaikanal, two at Theni and seven at Valparai), selected through a respondent-driven sampling strategy (Newing 2010).

The questionnaire, administered face to face with respondents, was standardized for the native languages (Tamil and Malayalam) and English. Respondents were asked to rate stakeholders other than themselves for conserving biodiversity on a scale of 0 (zero efficiency) to 5 (maximum positive efficiency). Efficiency in biodiversity conservation was explained as the amount of positive assistance the stakeholders provided towards conserving biodiversity. Though questionnaires were not undertaken with political leaders, they were included as a stakeholder in biodiversity conservation to gain exploratory insight of their role from the other key stakeholders. Since interviewed stakeholders also rated political leaders, it allowed for this insight. Respondents were also asked to state issues if any, faced from other stakeholders or those within their community in relation to biodiversity conservation. Respondent characteristics - age, gender, education and monthly income were recorded.

Statistical analysis was undertaken using SPSS 11.5 for Windows. Means of overall stakeholder efficiency in accordance with study area and stakeholder type were calculated. Non-parametric tests, Kruskal-Wallis and Mann Whitney U-test were undertaken to find if any differences in efficiency occurred between the different stakeholders and amongst stakeholders towards one another. Whether the ratings of stakeholder efficiencies differed with respect to the respondent characteristics was also analysed. For the open-ended question of stakeholder issues, the responses were coded appropriately and summarised.

\section{RESULTS}

\section{Stakeholder Ratings}

The FD was rated as the stakeholder with the highest efficiency in biodiversity conservation followed by local communities, conservation researchers and politicians (Fig. 2). Statistically significant differences were found towards the efficiency of all the four stakeholders - FD (Kruskal-Wallis test, $\chi^{2}=23.8, \mathrm{df}=2, P<0.001$ ), researchers (Kruskal-Wallis test, $\chi^{2}=196.3, \mathrm{df}=2, P<0.0001$ ), political

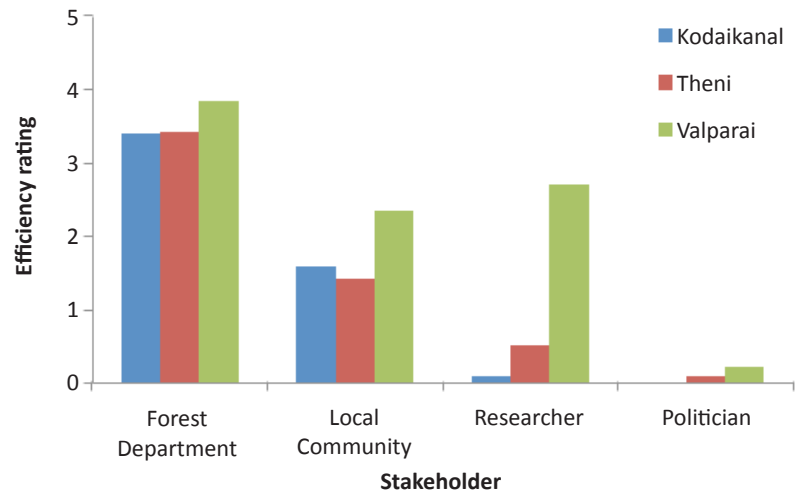

Figure 2. Stakeholder efficiency in biodiversity conservation as per overall ratings at three areas (Kodaikanal, Theni and Valparai) in the Western Ghats.

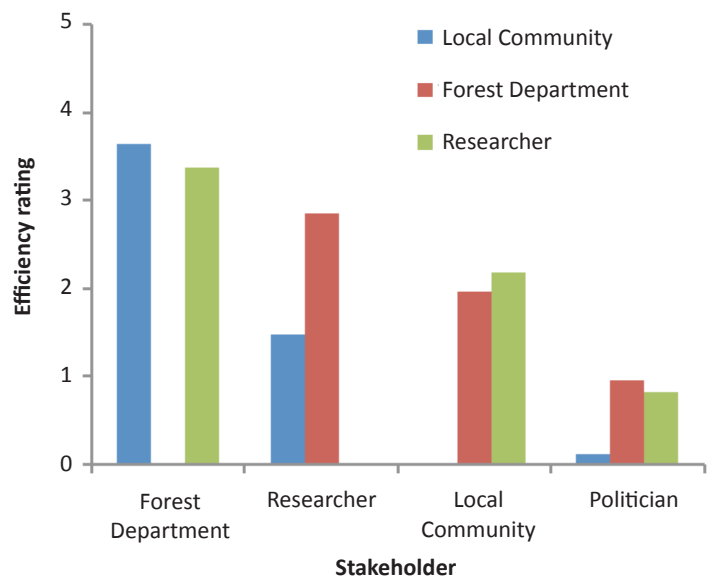

Figure 3. Stakeholder rating of the efficiency of other participating stakeholders involved in biodiversity conservation in the Western Ghats

leaders $\left(\chi^{2}=10.6, \mathrm{df}=2, P<0.01\right)$ and local communities (Kruskal-Wallis test, $\chi^{2}=6.4, \mathrm{df}=2, P=0.04$ ) in the three areas. The average efficiency ratings of the four stakeholders were comparatively higher in Valparai than at Kodaikanal and Theni (Fig. 2). There was also a higher rating for researchers than locals at Valparai.

Local communities and FD were rated similarly by the other stakeholders (Fig. 3). Researcher (Mann-Whitney U-test, 3062.5, $\mathrm{df}=1, P=0.001$ ) and political efficiency (Kruskal-Wallis test, $\chi^{2}=77.8, \mathrm{df}=2, P<0.001$ ) was however rated differently by the other stakeholders. Researchers were rated lower by local communities in comparison to the FD (Fig. 3). Similarly the FD rated politicians much lower than local communities and researchers (Fig. 3).

Research efficiency was found to vary significantly among the different age (Kruskal-Wallis test, $\chi^{2}=12.4$, $\mathrm{df}=3, P<0.001$ ) and education groups that rated them (Kruskal-Wallis test, $\chi^{2}=18.9, \mathrm{df}=3, P<0.001$ ). The age 
group above 50 years rated researcher efficiency higher $(2.2 \pm 0.3)$ than the other younger groups $(18-30=$ $1.5 \pm 0.2,31-40=1.4 \pm 0.1 \& 41-50=1.4 \pm 0.2$ ). Researcher efficiency was also found to increase with an increase in educational qualification (none $=1.0 \pm 0.2,1-8=1.4 \pm 0.1$ \& $9-12=2.0 \pm 0.2$ ) except at the graduate level among whom it reduced $(1.1 \pm 0.3)$.

Political efficiency was found to vary significantly among the different salary (Kruskal-Wallis test, $\chi^{2}=68.3$, $\mathrm{df}=3, P<0.001$ ) and education groups (Kruskal-Wallis test, $\left.\chi^{2}=22.6, \mathrm{df}=3, P<0.001\right)$. Lower income groups earning between $₹$ 0-5000 (no income $=0.3 \pm 0.2$, $1-2500=0.1 \pm 0.03,2501-5000=0.1 \pm 0.03$ ) rated political efficiency lower than those that earned above $₹ 5000$ $(0.7 \pm 0.2)$. With an increasing level of education, the political efficiency rating also increased (none $=0.1 \pm 0.04$, $1-8=0.2 \pm 0.04,9-12=0.1 \pm 0.04$, above $12=0.6 \pm 0.2$ ).

\section{Issues amongst stakeholders}

Livelihood issues attributed to each stakeholder's characteristic were expressed recurrently through the interviews. There was a pronounced perception among local communities that the FD was very strict, did not recognize their needs and dependency on firewood, and cared more for wildlife than the lives of the local people. Some FD officials were also known to derive bribes from local communities when they caught them collecting forest resources. Some locals feared the FD and claimed that in spite of extending help, the FD never reciprocated. A local settlement (Arsaredi, Meghamalai Wildlife Division) at Theni faced a situation of impending relocation and implored for assistance. They claimed to be brought into the landscape by the FD to setup silk cotton plantations in replacement of the native vegetation at the Reserve Forests. After the plantation initiative ceased and the FD's activities receded, they continued to live and farm around the area. However, the FD now wanted them to move away from the area. The local FD officials claimed that the local community's political connections aided the community from imminent FD action of their removal from the area.

Reduced effectiveness of the FD was attributed to a smaller work force and low salaries. This was perceived to cut back monitoring and implementation of conservation plans. Some FD officials lower in the hierarchy were dissatisfied over the inadequate facilities and equipment at their disposal for effectively conserving biodiversity.

The FD, researchers and local communities stressed the interference of politicians and their role in conservation-based disputes of encroachments in forest areas as well as illegal felling and sale of timber. Civil servants, political leaders, bureaucrats and lower level administrative workers were perceived to be poorly informed with regard to biodiversity conservation and adequate efforts should be taken to promote awareness among them.

\section{DISCUSSION}

\section{Forest Department}

The FD, accredited with the management of forested areas was rated with the highest efficiency in biodiversity conservation in the study areas. However, the results also suggest that the limited manpower of the Tamil Nadu FD reduced effective monitoring in areas such as Valparai (Kumara et al. 2004; Raman \& Mudappa 2003).

Accepting bribes from locals could be arising from unsatisfactory salaries and facilities. This condition has also created a business-as-usual attitude, where both stakeholders may find the existing system too convenient to change. Moreover, the organizational structure of the FD is characterised by hierarchy and a top-down information flow (Kumar \& Kant 2005), a reason why the FD officials expect the community members to function and be treated the same. Tenure insecurity among the FD and local communities is another reason for the constant sense of antagonism (Sekhar 2004) between both the stakeholders. Based on these issues, improved training for the forest guards and watchers as well as an inbuilt system that allows for greater interaction with the locals, and other stakeholders would help. Improving the working conditions for the FD personnel, providing incentives and working towards ensuring a better relationship with local communities would increase their efficiency further.

\section{Local Communities}

Local community efficiency in conserving biodiversity has been rated second to the FD at all the areas except at Valparai, where researchers were rated higher. However, FD officials rated local communities lower than researchers in the role they played in biodiversity conservation. This could have emerged out of the prevalent concern over local dependence on natural resources and FD officials being involved in a higher level of interaction with locals than researchers.

The local communities in turn perceived that the managing authorities were inconsiderate of their need of forest-based resources. Currently, as even protected areas are perceived to support the livelihoods of local communities associated with it (McNeely 1993), limited 
access forests like those that were part of this study, may need to do so. Apart from the new category of Community and Conservation Reserves where multistakeholder interests are to be considered, initiatives such as Eco-development Committees and Village Forest Committees related to protected areas have been successful in some states of the country. For the ecodevelopment committees at Periyar Tiger Reserve in Kerala, participation and collaboration has empowered local communities, improved relations between the protected area and local communities and has contributed in alleviating poverty (Periyar Tiger Reserve 2012).

The provision of free, alternative resources would also be readily accepted by local communities. The local community members have developed a negative attitude towards the FD, which could have risen from conflicts based on resource extraction, rude behaviour or harassment by FD officials (Macura et al. 2011). On account of this, local communities also expressed a sense of fear towards the FD. For many, the lack of legal land rights contributes to the fear and negative attitude. Additionally, inadequate or unsatisfactory fulfilment of assurances by the FD also reduces local communities' confidence in them (Sekhar 2004). Keeping in mind that local communities are the stakeholders with the largest numbers and generally reside closer to forested areas, building a positive relationship with them would be critical for biodiversity conservation.

\section{Researchers}

The lack of available literature on conservation issues in Kodaikanal and Theni, and very low researcher efficiency in these areas suggests a lack of conservationbased research. These two sites also lacked permanent field stations dealing with conservation research in contrast to Valparai. There was a prominent difference in the manner in which researchers' efficiency in biodiversity conservation was perceived by FD officials and local communities (Fig 3). Local communities rated their efficiency lower than FD officials, which suggests a lack of interaction with local communities, local perceptions that research may be unimportant, or absence of initiatives that involved on-ground conservation and sharing of knowledge. Locally situated field stations could also contribute to building better relationships with people. However, the research undertaken needs to be communicated, so as to inform local communities and, in a sense, give back to the community. Therefore, setting up of permanent field stations to initiate active research and outreach activities could benefit biodiversity conservation especially at Kodaikanal and Theni. Outreach initiatives need to be aimed at age groups below 50 years and college graduates to bring about greater exposure for biodiversity conservation and research initiatives.

\section{Political leaders}

Politicians have been rated with the lowest efficiency in biodiversity conservation, as they are known to intervene with "development" initiatives that threaten biodiversity conservation. An example of political intervention concerning a hotel construction in Kodaikanal has been discussed by Viraraghavan (2011) wherein the construction of seven-floors against the twofloor norm in commercial-use land as per the Kodaikanal Master Plan was aided by the State Government. The Kodaikanal Municipality was then found to have 1503 buildings constructed without any sanctions, of which 233 had zoning restriction violations (Viraraghavan 2011). In a rapidly growing country like India, the needs and interests of people may often be put ahead of biodiversity conservation. Therefore, conserving biodiversity may not be necessary for political leaders to gain mass support, however this could be achieved by catering to the resource needs of local communities. The interdependence of these two stakeholders though weak at times or reduced to a few meetings each fiveyear term during the elections, could be an important link for discussing and resolving conservation issues. Interactions with political leaders may need to be pursued by other stakeholders to devise strategies that integrate the needs of local communities and biodiversity conservation.

\section{CONCLUSION}

Our study has thrown light on the differing stakeholder views towards biodiversity conservation in a 'Biodiversity Hotspot' like the Western Ghats. It highlights the importance of integrating multiple stakeholders to determine ways and to begin resolving issues related to biodiversity conservation. Differing perceptions and consequent interests among stakeholders is a challenge which needs to be addressed for effective biodiversity conservation. Greater interaction between each stakeholder may improve perceptions towards each other. While perceptions cannot be induced, a basis for building positive relationships can be met through interaction, collaboration and consultations with key stakeholders, as an initial step towards improved 
collaborative biodiversity conservation.

\section{REFERENCES}

Andrade, G.S.M. \& J.R. Rhodes (2012). Protected Areas and Local Communities: an Inevitable Partnership toward Successful Conservation Strategies? Ecology and Society 17(4): 14; http:// dx.doi.org/10.5751/ES-05216-170414

Ayyanar, M., K. Sankarasivaraman, S. Ignacimuthu \& T. Sekar (2010). Plant species with ethno botanical importance other than medicinal in Theni district of Tamil Nadu, southern India. Asian Journal of Experimental Biological Sciences 1(4): 765-771.

Bagyaraj, M. \& B. Gurugnanam (2011). Significance of Morphometry Studies, Soil Characteristics, Erosion Phenomena and Landform Processes Using Remote Sensing and GIS for Kodaikanal Hills, A Global Biodiversity Hotpot in Western Ghats, Dindigul District, Tamil Nadu, South India. Research Journal of Environmental and Earth Sciences 3(3): 221-233.

Bhupathy, S., G. Srinivas, N. Sathishkumar, M. Murugesan, S. Babu, R. Suganthasakthivel \& P. Sivakumar (2012). Diversity and conservation of selected biota of the Megamalai landscape, Western Ghats, India. Current Science 102(4): 590-595.

Brown, K. (2002). Innovations for conservation and development. The Geographical Journal 168: 6-17; http://dx.doi.org/10.1111/14754959.00034

CARDS (Centre for Agricultural and Rural Developmental Studies) (2008). National Agricultural Development Programme; District Agricultural Plan - Theni District. <http://agritech.tnau.ac.in/ govt_schemes_services/pdf/govt_schemes_nadp_dap_Theni.pdf $>$. Online version dated 24 May 2012.

Daniels, R.J.R. (2003). Impact of tea cultivation on anurans in the Western Ghats. Current Science 85(10): 1415-1422.

District Collectorate Theni (2009). Tourist Attractions in Theni District.

< http://www.theni.tn.nic.in/Tourism.asp>. Online version dated 24 May 2012.

Kumara, H.N., M.A. Kumar, A.K. Sharma, H.S. Sushma \& M. Singh (2004). Diversity and management of wild mammals in tea gardens in the rainforest regions of the Western Ghats, India: A case study from a tea estate in the Anaimalai Hills. Current Science 87: 12821287.

Kumar, S. \& S. Kant (2005). Bureaucracy and new management paradigms: modeling foresters' perceptions regarding communitybased forest management in India. Forest Policy and Economics 7: 651-669; http://dx.doi.org/10.1016/j.forpol.2004.02.001

Macura, B., F. Zorondo-Rodriguez, M. Grau-Satorras, K. Demps, M. Laval, C. Garcia \& V. Reyes-Garcia (2011). Local community attitudes towards forests outside protected areas in India. Impact of legal awareness, trust and participation. Ecology and Society 16(3): 10; http://dx.doi.org/10.5751/ES-04242-160310

Madhusudan, M.D., K. Shanker, A. Kumar, C. Mishra, A. Sinha, R. Arthur, A. Datta, M. Rangarajan, R. Chellam, G. Shahabuddin, R. Sankaran, R., M. Singh, U. Ramakrishnan \& P.D. Rajan (2006). Science in the wilderness: the predicament of scientific research in India's wildlife reserves. Current Science 91: 1015-1019.

McNeely, J.A. (1993). Economic incentives for conserving biodiversity: Lessons for Africa. Ambio 22(2/3): 144-150.

Muthukumar, S., N. Ayyappan, N. Parthasarthy, D. Mudappa, T.R.S Raman, M.A. Selwyn \& L.A. Pragasan (2006). Plant community structure in tropical rainforest fragments of the Western Ghats, India. Biotropica 38(2): 143-160; http://dx.doi.org/10.1111/j.1744 7429.2006.00118.x

Newing, H., (2010). Conducting Research in Conservation: Social Science Methods and Practice. Routledge, London.

Niraj, S.K., P.R. Krausman \& V. Dayal (2012). A stakeholder perspective into wildlife policy in India. The Journal of Wildlife Management 76(1): 10-18; http://dx.doi.org/10.1002/jwmg.263
Appendix 1. The 25 limited access forest sites in the Western Ghats, their ownership and area surveyed

\begin{tabular}{|c|c|c|c|}
\hline Site No. & Studysite & Ownership & Area \\
\hline 1 & Gundupatti & Government & Kodaikanal \\
\hline 2 & Machur & Government & Kodaikanal \\
\hline 3 & Pannaikadu & Government & Kodaikanal \\
\hline 4 & Perumal Malai & Government & Kodaikanal \\
\hline 5 & Kukkal & Government & Kodaikanal \\
\hline 6 & $\mathrm{HCRI}^{\mathrm{b}}$ & Government & Theni \\
\hline 7 & Korangani & Government & Theni \\
\hline 8 & Kumbhakarai & Government & Theni \\
\hline 9 & Meghamalai & Government/Private & Theni \\
\hline 10 & Paliangudi & Government & Theni \\
\hline 11 & Sothuparai & Government & Theni \\
\hline 12 & Vellapar Kovil & Government & Theni \\
\hline 13 & Vellimalai & Private & Theni \\
\hline 14 & Injipara & Private & Valparai \\
\hline 15 & Korangmudi & Private & Valparai \\
\hline 16 & Old Valparai & Private & Valparai \\
\hline 17 & Pannimade & Private & Valparai \\
\hline 18 & Puthuthotam & Private & Valparai \\
\hline 19 & Sellaliparai & Private & Valparai \\
\hline 20 & Sholayur Dam & Private & Valparai \\
\hline 21 & Srikundra & Private & Valparai \\
\hline 22 & Surlimalai & Private & Valparai \\
\hline 23 & Tantea & Government & Valparai \\
\hline 24 & Urulikkal & Private & Valparai \\
\hline 25 & Varrattuparai & Private & Valparai \\
\hline
\end{tabular}

Pathak, N. (2009). Community conserved areas in India an overview. In: Pathak, N. (ed.). Community Conserved Areas in India A Directory. Kalpavriksh, Pune, 500pp.

Periyar Tiger Reserve (2012). India Eco Development Project. http:// periyartigerreserve.org/Periyar/html/html/iedp_positiveimpact. htm Online version dated 21 March 2013.

Raju, K. (2002). Encroachments a threat to Megamalai hills sanctuary plan. The Hindu. <http://hindu.com/2002/12/16/ stories/2002121604430500.htm>. Online version dated 24 May 2012.

Raman, T.R.S. \& D. Mudappa (2003). Bridging the gap: Sharing responsibility for ecological restoration and wildlife conservation on private lands in the Western Ghats. Social Change 33(2\&3): 129141; http://dx.doi.org/10.1177/004908570303300309

Sekhar, U. (2004). Local Versus Expert Knowledge in Forest Management in a Semi-Arid part of India. Land Degradation \& Development 15: 133-142; http://dx.doi.org/10.1002/ldr.593

Taghioff, D. \& A. Menon (2010). Can a Tiger Change Its Stripes? The Politics of Conservation as Translated in Mudumalai. Economic \& Political Weekly 45(28): 69-76.

Viraraghavan, M.S., (2011). Hill Stations in the Western Ghats, Kodaikanal - A Case Study, Ed. W.G.E.E. Panel. Ministry of Environment and Forestry, Government of India, New Delhi.

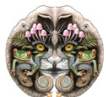


Author Details: ARUN KANAGAVEL, keen on research that would inform conservation action, is interested in social dimensions that influence perception of nature and its conservation, and the potential of local communities in linking biodiversity conservation and protected areas.

REVATI PANDYA is interested in natural resource management, its plurality and understanding the same through stakeholder perceptions as a basis for conflict resolution. In relation to this, she is specifically interested in the potential of protected areas in conservation and exploring the nature of collaborative management.

ADITYA PRITHVI is interested in understanding the effects of income disparity in societies and its effect on perception towards day to day events including wildlife conservation. $\mathrm{He}$ is also interested in the interaction between the various strata of society. RAJEEV RAGHAVAN is interested in interdisciplinary research, advocacy and policy making related to the conservation, management and sustainable use of nature and natural resources.

Author Contribution: AK was involved in designing, undertaking the study, data analysis and manuscript preparation. $\mathrm{RP}, \mathrm{AP}$ and $\mathrm{RR}$ were involved in manuscript preparation. 